OPEN ACCESS

Edited by:

Edmundo Acevedo,

Universidad de Chile, Chile

Reviewed by:

Cándido López-Castañeda, Colegio de Postgraduados, Mexico

Nidia Brunel-Saldias,

University of Talca, Chile

${ }^{*}$ Correspondence:

Yinglong Chen

yinglongchen@hotmail.com

${ }^{\dagger}$ These authors have contributed equally to this work.

Specialty section:

This article was submitted to Crop Science and Horticulture, a section of the journal Frontiers in Plant Science

Received: 24 February 2017 Accepted: 12 April 2017 Published: 01 May 2017

Citation:

Fang Y, Du Y, Wang J, Wu A,

Qiao S, Xu B, Zhang S, Siddique KHM and Chen Y (2017)

Moderate Drought Stress Affected

Root Growth and Grain Yield in Old, Modern and Newly Released Cultivars of Winter Wheat.

Front. Plant Sci. 8:672. doi: 10.3389/fpls.2017.00672

\section{Moderate Drought Stress Affected Root Growth and Grain Yield in Old, Modern and Newly Released Cultivars of Winter Wheat}

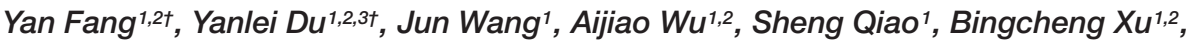 \\ Suiqi Zhang1,2, Kadambot H. M. Siddique ${ }^{4}$ and Yinglong Chen ${ }^{1,2,4 *}$

\begin{abstract}
${ }^{1}$ State Key Laboratory of Soil Erosion and Dryland Farming on the Loess Plateau, Northwest A\&F University, Yangling, China, ${ }^{2}$ Institute of Soil and Water Conservation, Chinese Academy of Sciences and Ministry of Water Resources, Yangling, China, ${ }^{3}$ State Key Laboratory of Grassland Agro-ecosystems, Institute of Arid Agroecology, School of Life Sciences, Lanzhou University, Lanzhou, China, ${ }^{4}$ The UWA Institute of Agriculture, and UWA School of Agriculture and Environment, The University of Western Australia, Perth, WA, Australia
\end{abstract}

To determine root growth and grain yield of winter wheat (Triticum aestivum $L$ ) under moderate drought stress, a nursery experiment and a field trial were conducted with or without water stress using three representative cultivars released in different years: CW134 (old landrace), CH58 (modern cultivar) and $\mathrm{CH} 1$ (new release). In the nursery experiment, plants were grown in soil-filled rhizoboxes under moderate drought (MD, $55 \%$ of field capacity) or well-watered (WW, $85 \%$ of field capacity) conditions. In the field trial, plots were either rainfed (moderate drought stress) or irrigated with $30 \mathrm{~mm}$ of water at each of stem elongation, booting and anthesis stages (irrigated). Compared to drought stress, grain yields increased under sufficient water supply in all cultivars, particular the newly released cultivar $\mathrm{CH} 1$ with $70 \%$ increase in the nursery and $23 \%$ in the field. When well-watered (nursery) or irrigated (field), $\mathrm{CH} 1$ had the highest grain yields compared to the other two cultivars, but produced similar yield to the modern cultivar (CH58) under water-stressed (nursery) or rainfed (field) conditions. When exposed to drought stress, CW134 had the highest topsoil root dry mass in topsoil but lowest in subsoil among the cultivars at stem elongation, anthesis, and maturity, respectively; while $\mathrm{CH} 1$ had the lowest topsoil and highest subsoil root dry mass at respective sampling times. Topsoil root mass and root length density were negatively correlated with grain yield for the two water treatments in nursery experiment. When water was limited, subsoil root mass was positively correlated with thousand kernel weight (TKW). In the field trial, $\mathrm{CH} 1$ and $\mathrm{CH} 58$ used less water during vegetative growth than $\mathrm{CW} 134$, but after anthesis stage, $\mathrm{CH} 1$ used more water than the other two cultivars, especially in the soil profile below $100 \mathrm{~cm}$, which was associated with the increased TKW. This study demonstrated that greater root mass and root length density in subsoil layers, with enhanced access to subsoil water after anthesis, contribute to high grain yield when soil water is scarce.

Keywords: drought stress, root mass, root length density, semi-arid Loess Plateau, Triticum aestivum 


\section{INTRODUCTION}

Wheat (Triticum aestivum L.) is the most widely grown cereal crop. The primary objective of most breeding programs is the development of high-yielding genotypes and improvement of grain yield potential (Foulkes et al., 2009). Since the Green Revolution, wheat yields have increased in many regions of the world (Gewin, 2010). To cope with the future demands for food, the yield of wheat and its yield potential under water-limited conditions needs to increase because farmland is increasingly being threatened by drought stress around the world (del Pozo et al., 2016). In addition to yield potential, yield stability (the selection of genotypes with more stable performance) remains a key objective for crop breeders (Slafer and Kernich, 1996). Becker and Leon (1988) believe that a successful genotype should produce consistently high yields over a wide range of environmental conditions, with a concomitant increase in stress tolerance (Tollenaar and Lee, 2002), such as drought stress (del Moral et al., 2003). There is evidence that modern cultivars with higher yields respond better to environmental change and have greater yield potential but less yield stability than older cultivars (Siddique et al., 1989a,b; Loss and Siddique, 1994; Fufa et al., 2005; Acreche et al., 2008). These studies focused mainly on shoot traits, with root studies often overlooked.

Drought is considered as one of the most important environmental stresses (Cattivelli et al., 2008). Improving yield under drought stress is an essential breeding target (Cattivelli et al., 2008). Drought stress can reduce wheat yields by up to $50 \%$ (Reynolds et al., 2007) due to significant reductions in plant growth and shoot production (Ehdaie et al., 2008, 2012). Several shoot-related physiological and morphological traits related to grain yield under drought conditions have been identified (Edmeades et al., 1999; Araus et al., 2002; Richards et al., 2002; Abdolshahi et al., 2015). However, root-related traits have been largely neglected by breeders due to the lack of straightforward, efficient methods for studying root systems in soil (Manschadi et al., 2006; Den Herder et al., 2010). Root system is the major plant organ for water and nutrient acquisition and influence plant growth and grain productivity (Ehdaie et al., 2012; Palta and Yang, 2014).

There are contrasting research reports on the value of the root system under drought stress for grain yield. One argument is that a relatively large root system is essential for crops grown in drought areas to absorb more soil water and relief drought stress (Palta et al., 2011; Ehdaie et al., 2012). An alternative view is that since the roots are a major sink for assimilates, reducing root mass increases the availability of assimilates for aboveground parts including grain yield (Siddique et al., 1990; Zhang et al., 1999; Song et al., 2009). Passioura (1983) and Zhu and Zhang (2013) argued that a small root system could have a positive effect on grain yield in water-limited situations. Genotypes with a large topsoil root system should be able to capture soil moisture from the topsoil during occasional spring rainfall and use it for grain filling (Palta et al., 2011; Ehdaie et al., 2012). In addition, a vigorous root system in the topsoil can absorb nutrients that are mostly concentrated in the upper layers of soil (Manske and Vlek, 2002). However, a large root mass in the topsoil layer may aggravate the effects of water stress and increase abscisic acid (ABA) levels, which would reduce stomatal conductance and photosynthesis (Ramachandra Reddy et al., 2004; Du et al., 2013). Root traits should be considered in the study of crop water-use efficiency (Raza et al., 2015).

A number of researchers reported genetic improvements in Chinese wheat (Song et al., 2009; Zhang et al., 2010; Zheng et al., 2011; Sun et al., 2014) and several studies have observed morphological and physiological changes in aboveground parts giving rise to yield increases under water-limited environments on the Loess Plateau (Zhang et al., 2009; Chen et al., 2011). A high photosynthetic rate in winter wheat was found in these areas (Sun et al., 2014). Roots play a vital role in water uptake, and thus affect photosynthetic rate, which associated with changes in yield, especially in the semi-arid areas (Reynolds et al., 2000; Sun et al., 2014). However, few studies examined winter wheat root systems in such regions. Here, three winter wheat cultivars, a newly released cultivar $\mathrm{CH} 1$, a modern cultivar CH58 and an old landrace CW134 (Chen et al., 2014), were selected to determine changes in the root system and the relationship between root growth and grain yield under drought and well-watered conditions. It was hypothesized that root system adaptive to drought stress was improved along with genetic improvements, and the changed root system of modern cultivar led to a higher yield stability and yield potential than the old landrace.

\section{MATERIALS AND METHODS}

\section{Plant Materials}

Three local cultivars of winter wheat (T. aestivum L.) with similar plant heights were used in both rhizobox experiment in a nursery and field trial. Changwu 134 (CW134) is a widely grown old landrace and Changhan 58 (CH58) is a modern cultivar released in 2004. The both cultivars were among the most successful releases of their respective eras, based on the area cropped and cultivation period in the region. Changhang $1(\mathrm{CH} 1)$ is a newly released cultivar (2014) and is the current common winter wheat cultivar grown on the Loess Plateau. The average yields of cultivars CW134, CH58 and CH1 were 4500, 5300, and $5500 \mathrm{~kg}$ $\mathrm{hm}^{-2}$ based on their cultivation by local farmers on the Loess Plateau. The three cultivars were developed for the semi-arid dryland agricultural area on the Loess Plateau, China. Seeds were obtained from the Institute of Crop Germplasm Resources, Chinese Academy of Agricultural Sciences, Beijing, China.

\section{Rhizobox Experiment Experimental Design, Establishment, and Maintenance}

A soil-filled rhizobox experiment was conducted from October 2014 to June 2015 in a nursery in Yangling $\left(108^{\circ} 4^{\prime} 28^{\prime \prime} \mathrm{E}\right.$, $34^{\circ} 16^{\prime} 56^{\prime \prime} \mathrm{N}, 500 \mathrm{~m}$ a.s.l), Shaanxi Province, Northwest of China. A randomized complete block design with three wheat cultivars and two water treatments was used. Two water treatments were: (1) moderate drought stress (MD, 55\% field water capacity, FWC) and well-watered (WW, 85\% FWC). 
Rectangular rhizoboxes ( $400 \mathrm{~mm}$ wide, $600 \mathrm{~mm}$ subsoil, and $30 \mathrm{~mm}$ thick) were constructed with stainless steel frames and clear perspex on one side (6 mm thick). Each rhizobox was filled with $12 \mathrm{~kg}$ of sieved ( $2 \mathrm{~mm}$ mesh) air-dried soil, collected from the upper $20 \mathrm{~cm}$ of a cultivated field in Yangling, a typical Calcaric Regosol (FAO/UNESCO soil classification system; Wang et al., 2010). Gravimetric moisture content at field capacity was $26 \%$ and wilting point was $9 \%$. The soil organic matter content, total nitrogen $(\mathrm{N})$ and total phosphorus $(\mathrm{P})$ contents were 19.1, 0.93 , and $0.88 \mathrm{~g} \mathrm{~kg}^{-1}$, respectively. Soil alkali-hydrolysable $\mathrm{N}$ was $65.0 \mathrm{mg} \mathrm{kg}^{-1}$, rapidly available phosphorus was $17.9 \mathrm{mg}$ $\mathrm{kg}^{-1}$ and available potassium was $163.6 \mathrm{mg} \mathrm{kg}^{-1}$. Before sowing, base fertilizer, equivalent to $120 \mathrm{~kg} \mathrm{ha}^{-1} \mathrm{~N}\left(0.36 \mathrm{~g} \mathrm{~kg}^{-1} \mathrm{~N}\right.$ as urea) and $60 \mathrm{~kg} \mathrm{ha}^{-1} \mathrm{P}\left(0.68 \mathrm{~g} \mathrm{~kg}^{-1}\right.$ of $\mathrm{P}_{2} \mathrm{O}_{5}$ as calcium superphosphate), was applied to the soil to ensure sufficient nutrition supply. The rhizoboxes were weighed and watered at 08:00 and 16:00 h every 2 days throughout the experimental period. Six seeds of each cultivar were planted in each rhizobox at a depth of $30 \mathrm{~mm}$ in October. Seedlings were thinned to three per rhizobox following emergence. After thinning, the soil in the rhizoboxes was covered with a layer of perlite to reduce water evaporation. There were six replicate rhizoboxes in each treatment and the rhizoboxes were arranged randomly in a rainout shelter.

\section{Plant Sampling and Assessments}

Plants were assessed at stem elongation stage (2 March) and at maturity (11 May) with three rhizoboxes for each assessment per treatment. At stem elongation stage, tiller number and leaf area (CID Inc, Camas, WA, USA) of each plant were recorded. At maturity, spike number, number of grains per rhizobox, average thousand kernel weight (TKW) and grain yield were determined. At each harvest, aboveground parts were excised at the root/shoot interface, dried for $24 \mathrm{~h}$ at $75^{\circ} \mathrm{C}$ and then weighed. The harvest index (HI) at the maturity assessment was calculated using the following equation:

$$
\mathrm{HI}=\text { grain weight/total aboveground dry weight }
$$

After removal of shoot, the rhizoboxes were laid on the steel side to remove the perspex panel for sampling roots. The soil with roots in each rhizobox was separated into $0-20 \mathrm{~cm}$ (topsoil) and 20-60 cm (subsoil) layers. Roots in each layer were washed carefully by hand, and remove any attached soil. Washed roots were placed in plastic bags and stored at $4^{\circ} \mathrm{C}$. Roots were then scanned at 600 pixels per $\mathrm{mm}$ and root images were analyzed using WinRHIZO (Regent Instruments Inc., Québec City, QC, Canada) as described by Himmelbauer et al. (2004). Root length density ( $\mathrm{RLD}, \mathrm{cm} \mathrm{cm}^{-3}$ ) calculated as follows:

$$
\text { RLD }=\text { root length/soil volume }
$$

Scanned roots were dried in a forced-air dryer for $24 \mathrm{~h}$ at $75^{\circ} \mathrm{C}$. Topsoil and subsoil root mass and total root mass were determined. The ratio of root to shoot mass was calculated.

\section{Field Experiment}

\section{Experimental Design, Establishment, and Maintenance}

A field experiment was conducted from October 2015 to June 2016 at Changwu Agro-ecological Experiment Station of Chinese Academy of Sciences, Shaanxi Province, China (107 $40^{\prime} 30^{\prime \prime}$ E, $35^{\circ} 14^{\prime} 30^{\prime \prime} \mathrm{N}, 1200 \mathrm{~m}$ a.s.l.). The mean annual temperature is $9.1^{\circ} \mathrm{C}$, and the long-term average annual precipitation is $584 \mathrm{~mm}$ (1957-2001), with 68\% rainfall between June and September. The average frost-free period is 194 days per year. The soil is a typical Calcaric Regosol (FAO/UNESCO soil classification system; Wang et al., 2010) which consists of $59 \%$ silt, $37 \%$ clay, and $4 \%$ sand with a $\mathrm{pH}$ of 8.4 . It has organic matter content of $11.8 \mathrm{~g} \mathrm{~kg}^{-1}$, total $\mathrm{N}$ content of $0.87 \mathrm{~g} \mathrm{~kg}^{-1}$, mineralized $\mathrm{N}$ of $3.15 \mathrm{mg} \mathrm{kg}^{-1}$, Olsen-P of $14.4 \mathrm{mg} \mathrm{kg}^{-1}$, and $\mathrm{NH}_{4} \mathrm{OAc}$-extractable $\mathrm{K}$ of $144.6 \mathrm{mg} \mathrm{kg}^{-1}$ (Gong et al., 2007). The soil bulk density is $1.36 \mathrm{~g} \mathrm{~cm}^{-3}$, and the permanent wilting coefficient and field capacity is $10 \%$ and $26 \%$ (determined gravimetrically), respectively.

A randomized block design with three wheat cultivars, two water treatments was used. There were three replicate plots per treatments. Seeds were sown at $5 \mathrm{~cm}$ deep in rows $20 \mathrm{~cm}$ apart with a total density of 225 seeds $\mathrm{m}^{-2}$. The water treatments were (1) rainfed (RF), and (2) irrigated (IR) with $30 \mathrm{~mm}$ of water applied at the beginning of stem elongation (29 March), booting (28 April) and anthesis (22 May), respectively, using the flood irrigation method by measuring the amount of water applied with a flow meter.

\section{Plant Sampling and Assessment}

Plants were harvested at stem elongation (14 April), anthesis (15 May) and physiological maturity (25 June). In each plot, plants in $1 \mathrm{~m}^{2}$ were used for the assessment. At stem elongation and anthesis, 20 representative plants were sampled to measure leaf area (CID Inc, Camas, WA, USA) and tiller number. At maturity, grain yield, spike number, grain number, TKW and HI were determined. Plant tissues were dried in a forced draft oven at $75^{\circ} \mathrm{C}$.

Root samples were collected at stem elongation and anthesis stages. Roots were collected from the soil profile $(0-100 \mathrm{~cm})$ using a root corer with a diameter of $9 \mathrm{~cm}$. The soil profile was divided into two layers, $0-20 \mathrm{~cm}$ considered as topsoil and $20-100 \mathrm{~cm}$ as subsoil. Three plants per plot were selected for sampling roots. Three cores were taken for each plant with one centered over the cut stem of the sampled plants and the other two from the midpoint between the rows. The root samples were washed free of soil through a sieve with $0.4 \mathrm{~mm}$ mesh. The cleaned roots were placed in plastic bags and stored at $4^{\circ} \mathrm{C}$, and then scanned. Root mass and RLD were measured and calculated as described for the rhizobox experiment.

\section{Soil Moisture}

The soil water content was measured gravimetrically. Soil moisture was recorded at sowing, stem elongation, anthesis and maturity by coring using an auger of about $9 \mathrm{~cm}$ diameter. The soil profile $0-200 \mathrm{~cm}$ was divided into 10 layers of $20 \mathrm{~cm}$ each and sampled in three replicates per layer. Evapotranspiration (ET, 
$\mathrm{mm}$ ) and water used for a given period was estimated from:

$$
\mathrm{ETc}=\mathrm{P}+\Delta \mathrm{W}
$$

Where $\Delta \mathrm{W}$ is the change in soil water stored in the $0-200 \mathrm{~cm}$ profile between two soil moisture content measurements, and $\mathrm{P}$ is the recorded rainfall.

\section{STATISTICAL ANALYSIS}

Data of plant growth, grain yield and root traits was subjected to two-way ANOVAs to test the main effects (cultivar and water treatment) and their interactions using Statistical Analysis System (SAS 9.3). Means were separated using Fisher's protected l.s.d. at the 5\% level of significance. Associations between parameters were examined by correlation analysis.

\section{RESULTS}

\section{Rainfall and Temperature Variation in the Field Trial}

Rainfall and temperature during the season are shown in Figure 1. In 2015, precipitation (197 $\mathrm{mm})$ during the fallow period (July-September) was $31 \%$ less than the longterm mean $(287 \mathrm{~mm})$. Moreover, the growing season was warmer and drier than average. Temperatures from November 2015 to April 2016 were higher than the long-term mean, especially in March and April, which were 7.0 and $13.1^{\circ} \mathrm{C}$, respectively, while the respective long-term averages were 4.3 and $10.7^{\circ} \mathrm{C}$. Rainfall was lower than the long-term mean $(304 \mathrm{~mm})$, with $216 \mathrm{~mm}$ during the growing season
(Figure 1), 29\% less than the long-term mean. Precipitation from March to April (44 mm) was 39\% less than the longterm mean $(73 \mathrm{~mm})$ and from May to June $(89 \mathrm{~mm})$ was $16 \%$ less than the long-term mean $(106 \mathrm{~mm})$, indicating that the experiment (if without irrigation) was subjected to moderate drought conditions before anthesis and after anthesis, respectively.

\section{Grain Yield and Yield Components}

Under water stressed condition, $\mathrm{CH} 1$ and $\mathrm{CH} 58$ did not differ in grain yield and grain number, respectively, in the both experiments (Table 1). CH1 had significantly higher TKW than CW134 and CH58 $(P<0.05)$. CH1 also had the highest HI in both experiments (Table 1). In the rhizobox experiment, cultivar $\mathrm{CH} 1$ produced the highest grain yield when well-watered $(P<0.05)$. The higher spike number and grains number per unit area also found in $\mathrm{CH} 1$, and especially the TKW, which was the highest under well-watered treatment. The field experiment produced similar results (Table 1). Compared with the waterdeficit treatments, yields of CW134, CH58 and CH1 in wellwatered treatments increased by 58,54 , and $70 \%$, respectively, in the rhizobox experiment; and by $14,6.3$, and $23 \%$, respectively, in the field experiment (Table 1). These findings imply that grain yield in the newly released cultivar $(\mathrm{CH} 1)$ has higher yield potential, but the modern cultivar $(\mathrm{CH} 58)$ has greater yield stability.

\section{Aboveground Growth}

At the stem elongation stage, the higher tiller number per unit area and leaf area/leaf area index (LAI) of CH58 led to the highest shoot mass and lowest root-shoot ratio under both water treatments in both experiments (Table 2). At anthesis in the field experiment, water-stressed $\mathrm{CH} 1$ had the lowest shoot mass and

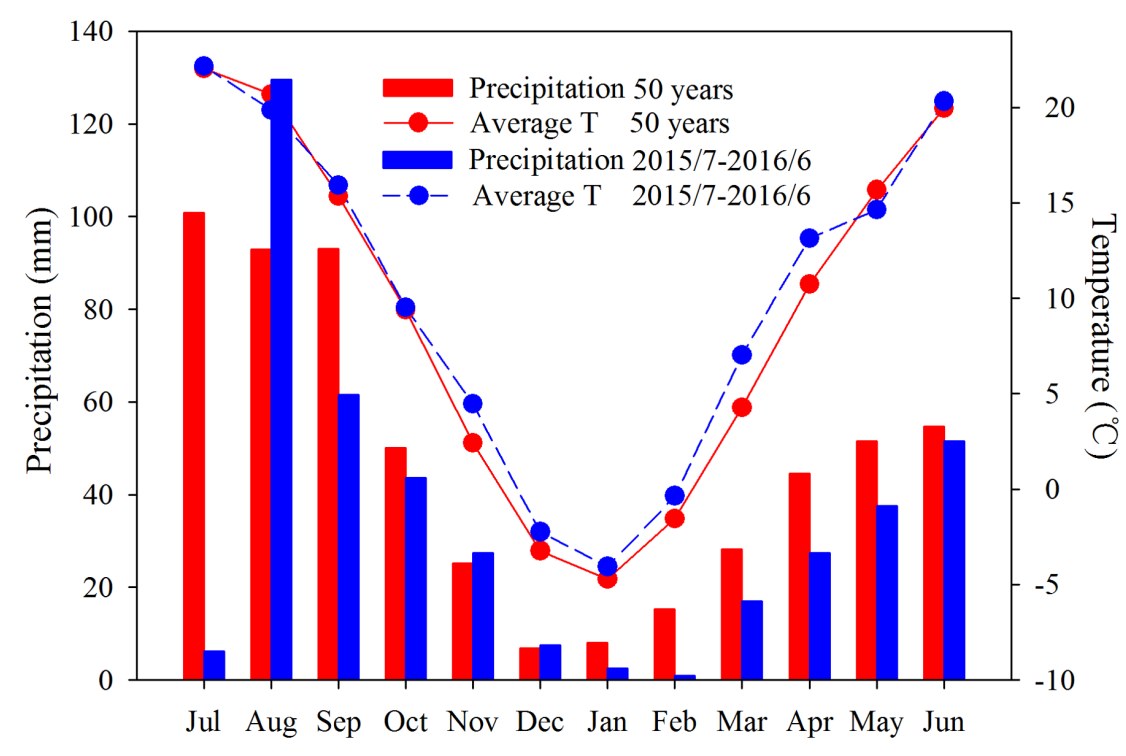

FIGURE 1 | Precipitation (bars) and temperature (lines) in 2015-2016 (blue bars and lines) and the long-term (50 years) mean (red bars and lines) at the experimental site at Changwu Agricultural Research Station, Shaanxi Province, China. 
TABLE 1 | Grain yield and yield components of three wheat cultivars (CW134, CH58, and CH1) under moderate drought stress (MD) and well-watered conditions (WW; 2015 Rhizobox experiment), or under rainfed (RF) and irrigated (IR) conditions (2016 Field trial).

\begin{tabular}{|c|c|c|c|c|c|c|}
\hline Treatments & & Grain yield (g) & Spike number & No. of grains & TKW (g) & HI \\
\hline \multirow[t]{2}{*}{$\mathrm{MD}$} & CW134 & $2.24 d$ & $4.29 b$ & $66.4 d$ & $34.2 \mathrm{c}$ & $0.23 c$ \\
\hline & $\mathrm{CH} 1$ & $2.40 c$ & $4.67 b$ & $69.9 \mathrm{~cd}$ & $36.1 \mathrm{~b}$ & $0.29 a$ \\
\hline \multirow[t]{2}{*}{ WW } & CW134 & $3.53 b$ & $6.22 \mathrm{a}$ & $109 b$ & $36.8 b$ & $0.23 c$ \\
\hline & $\mathrm{CH} 58$ & $3.69 b$ & $5.33 \mathrm{ab}$ & $116 a$ & $36.8 b$ & $0.23 c$ \\
\hline Cultivar & & * & ns & * & * & ** \\
\hline Water & & $* *$ & $* *$ & $* *$ & $*$ & ns \\
\hline Cultivar $\times$ Water & & $* *$ & $* *$ & $* *$ & ns & $*$ \\
\hline \multicolumn{7}{|l|}{2016 Field trial } \\
\hline $\mathrm{RF}$ & CW134 & $410 d$ & $519 \mathrm{~cd}$ & $896 d$ & $45.8 d$ & $0.28 c$ \\
\hline & $\mathrm{CH} 1$ & $567 a$ & $629 a$ & $1110 a$ & $51.1 \mathrm{a}$ & $0.34 a$ \\
\hline Cultivar & & $*$ & * & $* *$ & $*$ & $*$ \\
\hline Water & & $* *$ & $* *$ & $*$ & $*$ & $\mathrm{~ns}$ \\
\hline Cultivar $\times$ Water & & ns & ns & $* *$ & ns & ns \\
\hline
\end{tabular}

TABLE 2 | Tiller number, leaf area, shoot mass, and root-shoot ratio of three wheat cultivars (CW134, CH58, and CH1) at the stem elongation stage under moderate drought stress (MD) and well-watered conditions (WW; 2015 Rhizobox experiment), or under rainfed (RF) and irrigated (IR) conditions (2016 Field trial).

\begin{tabular}{|c|c|c|c|c|c|}
\hline Treatments & & Tiller number & Leaf area $\left(\mathrm{cm}^{2}\right)$ & Shoot mass (g) & Root-shoot ratio \\
\hline \multicolumn{6}{|c|}{2015 Rhizobox experiment } \\
\hline \multirow[t]{3}{*}{ MD } & CW134 & $6.67 c$ & $15.1 \mathrm{~d}$ & $2.62 c$ & $0.78 c$ \\
\hline & $\mathrm{CH} 58$ & $5.33 d$ & $16.6 c$ & $3.26 \mathrm{bc}$ & $0.58 d$ \\
\hline & $\mathrm{CH} 1$ & $5.67 d$ & $15.7 \mathrm{~cd}$ & $2.52 \mathrm{c}$ & $0.70 \mathrm{c}$ \\
\hline \multirow[t]{3}{*}{ WW } & CW134 & $8.33 b$ & $20.4 b$ & $3.87 b$ & $1.36 \mathrm{a}$ \\
\hline & $\mathrm{CH} 58$ & $9.33 a$ & $26.3 a$ & $5.69 a$ & $1.00 \mathrm{~b}$ \\
\hline & $\mathrm{CH} 1$ & $7.33 c$ & $27.4 \mathrm{a}$ & $3.99 b$ & $1.24 \mathrm{a}$ \\
\hline Cultivar & & $*$ & $* *$ & * & $*$ \\
\hline Water & & * & $*$ & $* *$ & * \\
\hline Cultivar $\times$ Water & & ns & $* *$ & $* *$ & $* *$ \\
\hline 2016 Field trial & & & $\operatorname{LAI}\left(\mathrm{m}^{2} \mathrm{~m}^{-2}\right)$ & & \\
\hline \multirow[t]{3}{*}{ RF } & CW134 & $1268 c$ & $1.80 \mathrm{~d}$ & $104 d$ & $1.13 a$ \\
\hline & $\mathrm{CH} 58$ & $1240 c$ & $2.44 a$ & $162 b$ & $0.61 d$ \\
\hline & $\mathrm{CH} 1$ & $1230 c$ & $2.24 b$ & $122 \mathrm{~cd}$ & $0.81 b$ \\
\hline \multirow[t]{3}{*}{$\mathbb{I R}$} & CW134 & $1353 b$ & $2.09 c$ & $146 b$ & $0.83 b$ \\
\hline & $\mathrm{CH} 58$ & $1418 \mathrm{a}$ & $2.35 \mathrm{ab}$ & $196 a$ & $0.70 \mathrm{c}$ \\
\hline & $\mathrm{CH} 1$ & $1350 \mathrm{~b}$ & $2.39 a$ & $142 \mathrm{bc}$ & $0.78 b c$ \\
\hline Cultivar & & $*$ & $*$ & $*$ & $*$ \\
\hline Water & & $* *$ & ns & * & ** \\
\hline Cultivar $\times$ Water & & ns & $*$ & ns & $*$ \\
\hline
\end{tabular}

Data for rhizobox experiment were calculated for each rhizobox, and for the field trial on one square meter. For each experiment, values in a column followed by the same letter are not significantly different at $P<0.05$ as determined by the Duncan's test. For ANOVA results in each experiment, ${ }^{*} P<0.05,{ }^{* *} P<0.01, n s$, not significant. 
TABLE 3 | Tiller number, leaf area index (LAI), shoot mass, and root-shoot ratio of three wheat cultivars (CW134, CH58, and CH1) at anthesis under rainfed (RF) and irrigated (IR) conditions in the field.

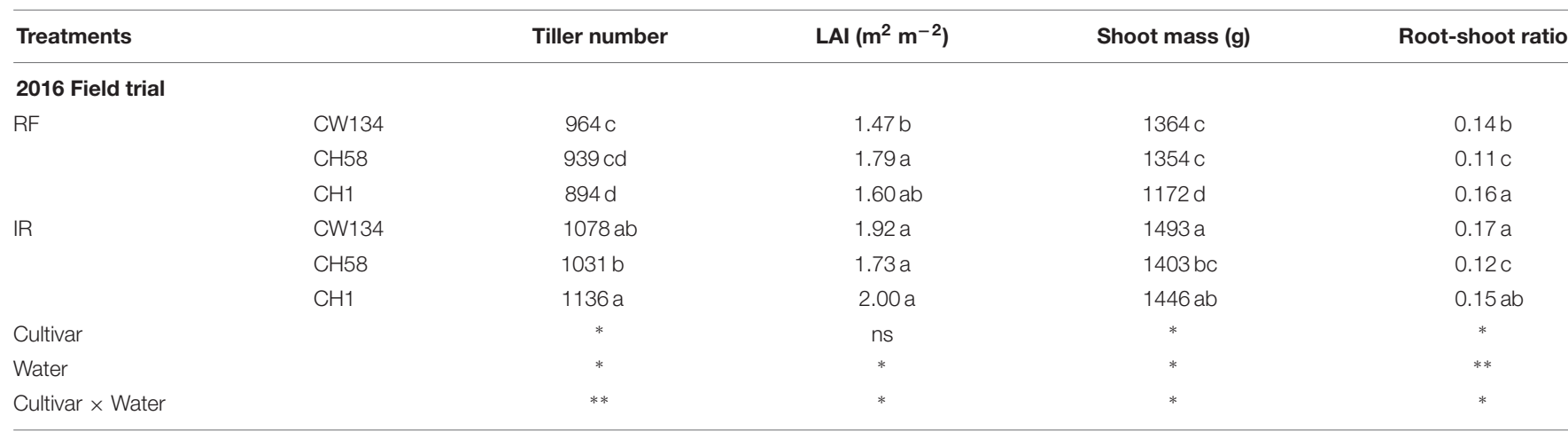

Data for field trial based on one square meter. Values in a column followed by the same letter are not significantly different at $P<0.05$ as determined by the Duncan's test. For ANOVA results, ${ }^{*} P<0.05,{ }^{* *} P<0.01$, ns, not significant.

tiller number while water-stressed CH58 had the lowest rootshoot ratio (Table 3). When well-watered, CH58 had the lowest shoot mass and tiller number per unit area. While CW134 and $\mathrm{CH} 1$ had similar tiller number per unit area, LAI, and shoot mass, as well as root-shoot ratio (Table 3). Well-watered plants of CW134, CH58 and CH1 had more shoot mass $(9.5,3.6$, and 23\%, respectively) than water-stressed plants (Table 3). This suggests that the shoots of the modern cultivar $\mathrm{CH} 58$ grew faster in the early season but were more stable than the other two cultivars by anthesis.

\section{Root Mass and Root Length Density}

Large variations in root mass (Figures 2, 3) and root length density (Figures 4,5 ) were found between water treatments

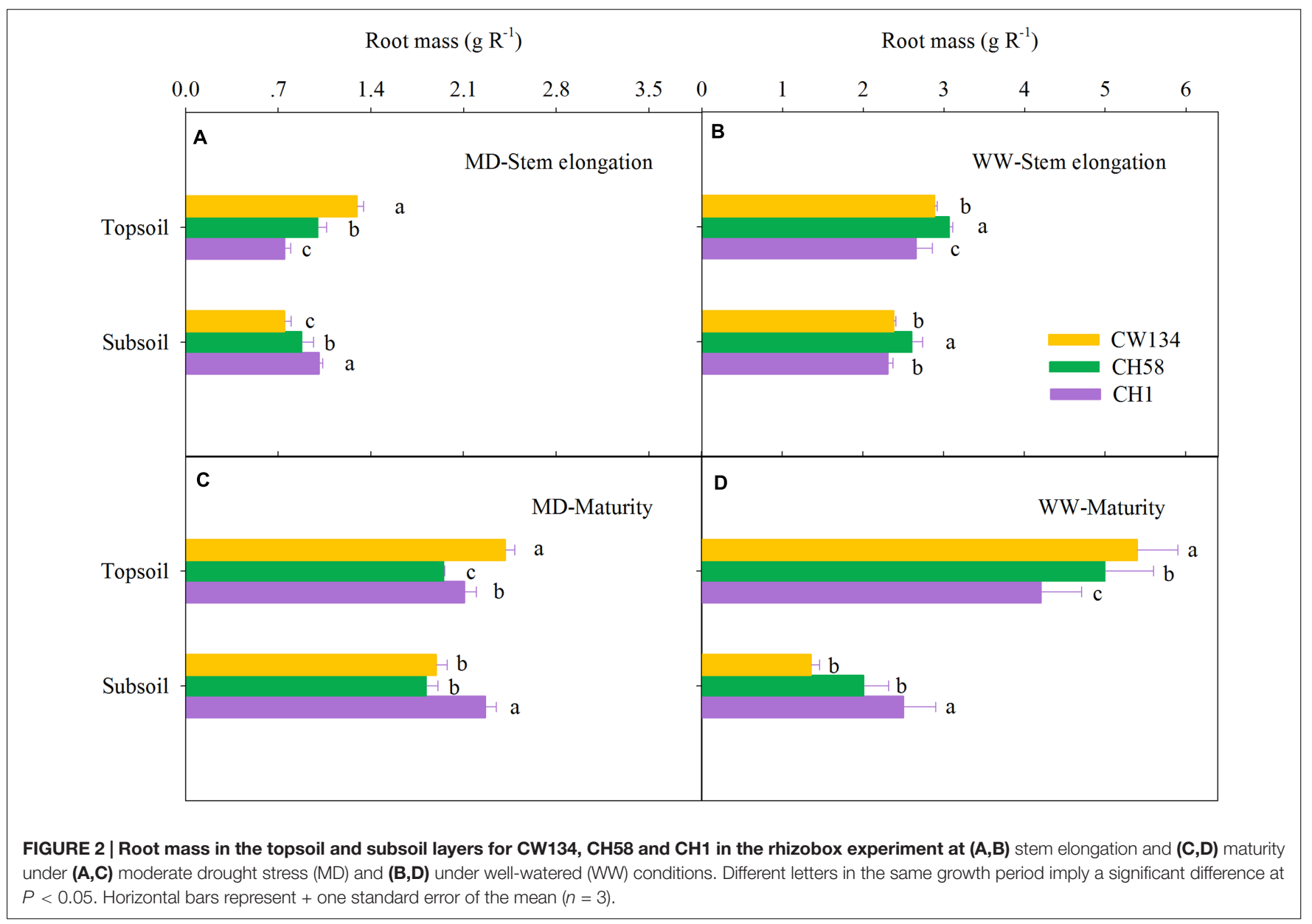




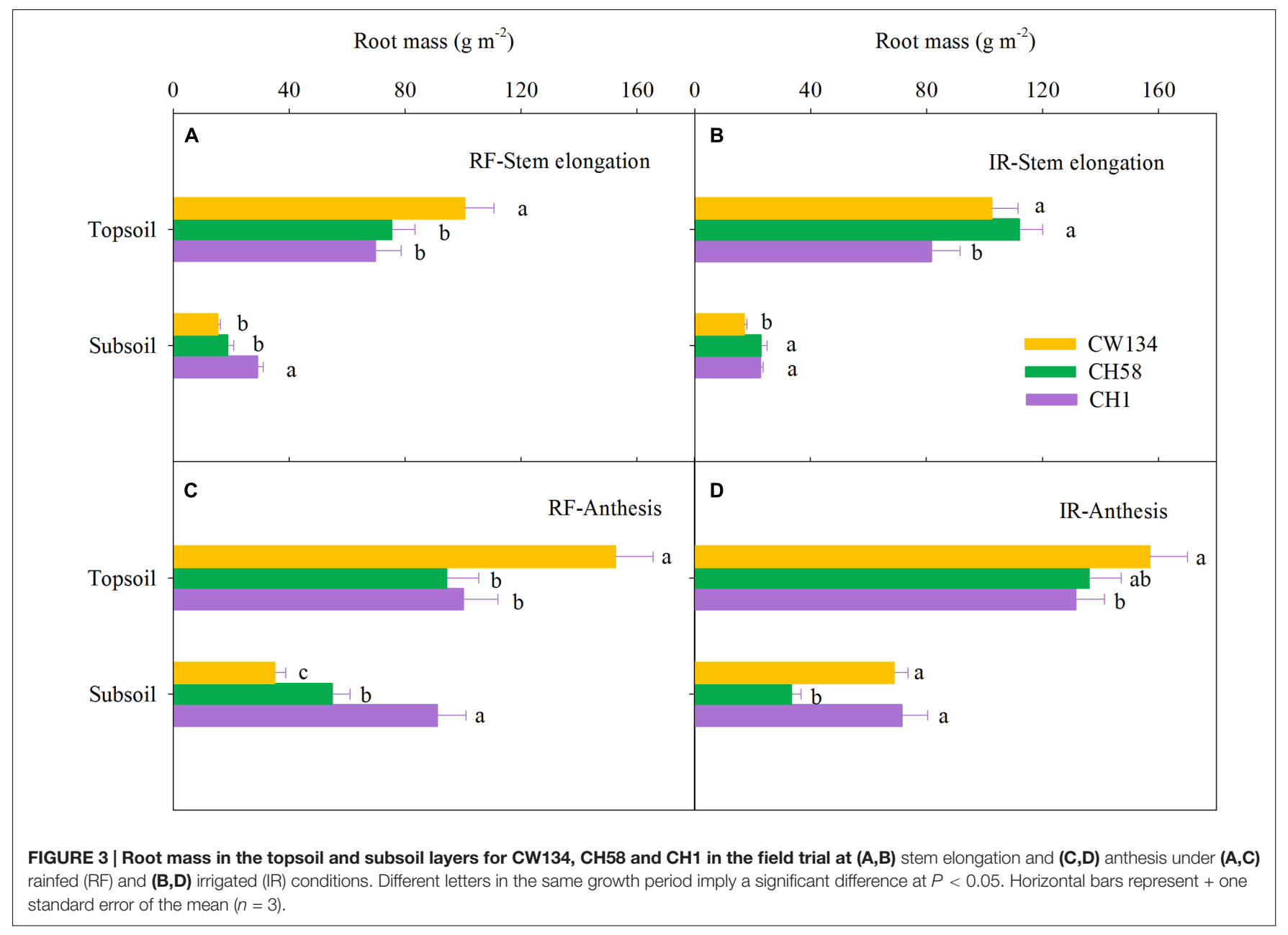

and among the three cultivars in the rhizobox experiment (Figures 2, 4) and in the field trial (Figures 3, 5). Under water stress, CW134 had the greatest topsoil (upper $20 \mathrm{~cm}$ ) root mass and RLD during stem elongation, anthesis and maturity in the rhizobox (Figures 2A,C, 4A,C) and field (Figures 3A,C, 5A,C) experiments. $\mathrm{CH} 1$ had the highest subsoil root mass (below $20 \mathrm{~cm}$ in rhizobox experiment, $20-100 \mathrm{~cm}$ in field experiment) and RLD in the rhizobox (Figures 2A,C, 4A,C) and field (Figures 3A,C, 5A,C) experiments. In the field experiment, rainfed $\mathrm{CH} 58$ and $\mathrm{CH} 1$ had similar topsoil root mass and RLD at stem elongation and anthesis (Figures 3A,C, 5C); At anthesis, rainfed CH58 had significantly higher subsoil root mass than CW134, but it was significantly lower than $\mathrm{CH} 1(P<0.05)$ (Figure 3C); CW134 and $\mathrm{CH} 58$ had similar RLD at both stem elongation and anthesis (Figures 5A,C).

In both experiments, at stem elongation, well-watered $\mathrm{CH} 58$ had the highest root mass and RLD in the topsoil and subsoil (Figures 2-5B), and well-watered $\mathrm{CH} 1$ remained the lowest root mass and RLD in the topsoil, except RLD in field experiment (Figures 2-5B). However, at anthesis, CH58 and CW134 had similar topsoil root mass and RLD under well-watered treatments (Figures 3D, 5D), and CH58 had the lowest subsoil root mass and RLD, which was significantly lower than the other two cultivars
(Figures 3D, 5D). CW134 and CH1 were similar in root mass (Figure 3D), but CH1 had significantly higher RLD than CW134 under irrigated condition (Figure 5D). These results indicate that, under water-deficit conditions, CW134 has the most topsoil root (root mass and RLD) and CH1 has the most subsoil root for the entire growth stage. Moreover, $\mathrm{CH} 58$ has smaller roots under water stress, but they grew better than other two cultivars in both soil layers when well-watered during early growth.

\section{Correlations between Root and Yield Traits}

Simple correlation coefficients between root traits and grain yield and yield traits showed that significant negative correlations between topsoil root (mass and RLD) with grain yield in the two water treatments in rhizobox experiment $(P<0.01$, Table 4). In contrast to the topsoil, subsoil root mass and RLD had significant positive correlations with grain yield in the waterstress treatments of both experiments $(P<0.05)$. Significant negative correlations between topsoil RLD and grain number were observed in well-watered and irrigated treatments in the field experiment $(P<0.05)$. When water limited, TKW and subsoil root mass were positively correlated in both experiments $(P<0.01$, Table 4). 


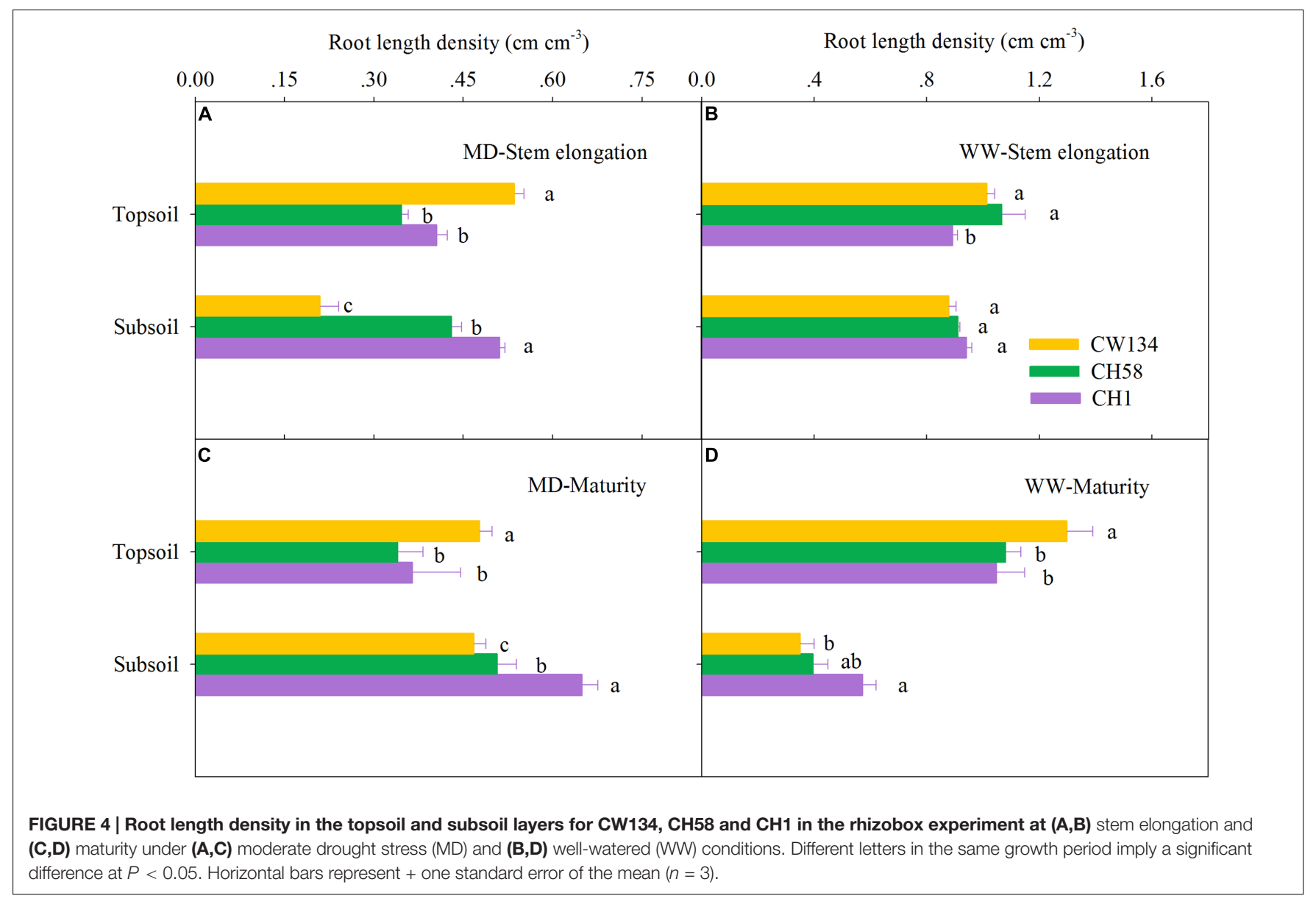

The above findings imply that root traits significantly influenced grain yield and its components. With water deficit, more roots in the topsoil layer and lower RLD in the subsoil layer resulted in lower grain yields. With sufficient water, higher RLD in the topsoil resulted in fewer grains per unit, while more subsoil root mass under water stress resulted in higher TKW, which may increase grain yield.

\section{Soil Water Content and Water Consumption}

In the field experiment, $\mathrm{CH} 1$ had significantly higher soil water content in the topsoil layer $(0-20 \mathrm{~cm})$ at stem elongation than CW134 and CH58 in both treatments, but the three cultivars did not differ at later growth stages (Figure 6). In subsoil layers $(20-100 \mathrm{~cm}), \mathrm{CW} 134$ had a high soil water content at stem elongation, especially below $80 \mathrm{~cm}$ (rainfed) and $60 \mathrm{~cm}$ (irrigated) (Figures 6A,D). At anthesis, the soil water content at below $100 \mathrm{~cm}$ profile was the least in CW134 and the highest in CH58 under water stress (Figure 6B), but no significant difference of soil water content was found among three cultivars under irrigated condition (Figure 6E). At maturity, $\mathrm{CH} 1$ had the lowest soil water content at 100-200 cm and CW134 was the highest under rainfed (Figure 6C). When under irrigation, $\mathrm{CH} 58$ had the highest soil water content in the soil profile below $100 \mathrm{~cm}$ (Figure 6F), with more deep soil water left at the end of the season.

The old cultivar CW134 had lower ET than the other two cultivars just before stem elongation in both rainfed and irrigation treatments $(P<0.01)$ (Figures $7 \mathbf{A}, \mathbf{B})$, but the reverse was true from stem elongation to anthesis (Figures $7 \mathrm{C}, \mathbf{D}$ ). After anthesis, the newly released cultivar $\mathrm{CH} 1$ used more water than other two cultivars under rainfed treatment (Figure 7E), but ET did not differ among three cultivars when under irrigated treatment (Figure 7F). Over the entire growing cycle, water use did not differ among the three cultivars in the rainfed treatment $(350,349$, and $352 \mathrm{~mm}$ in CW134, CH58 and $\mathrm{CH} 1$, respectively); however, when well-watered, $\mathrm{CH} 58$ consumed less water $(79 \mathrm{~mm})$ than $\mathrm{CH} 1(85 \mathrm{~mm})$ and CW134 $(82 \mathrm{~mm})$.

These findings clearly demonstrate that the cultivars changed their water consumption throughout the growing period. The old landrace cultivar CW134 used less soil water before stem elongation than the other two cultivars, but used more water between stem elongation and anthesis stages, leading to a lower soil water content after anthesis. However, $\mathrm{CH} 58$ and $\mathrm{CH} 1$ used less water during vegetative growth and more after anthesis, especially from subsoil layers. 


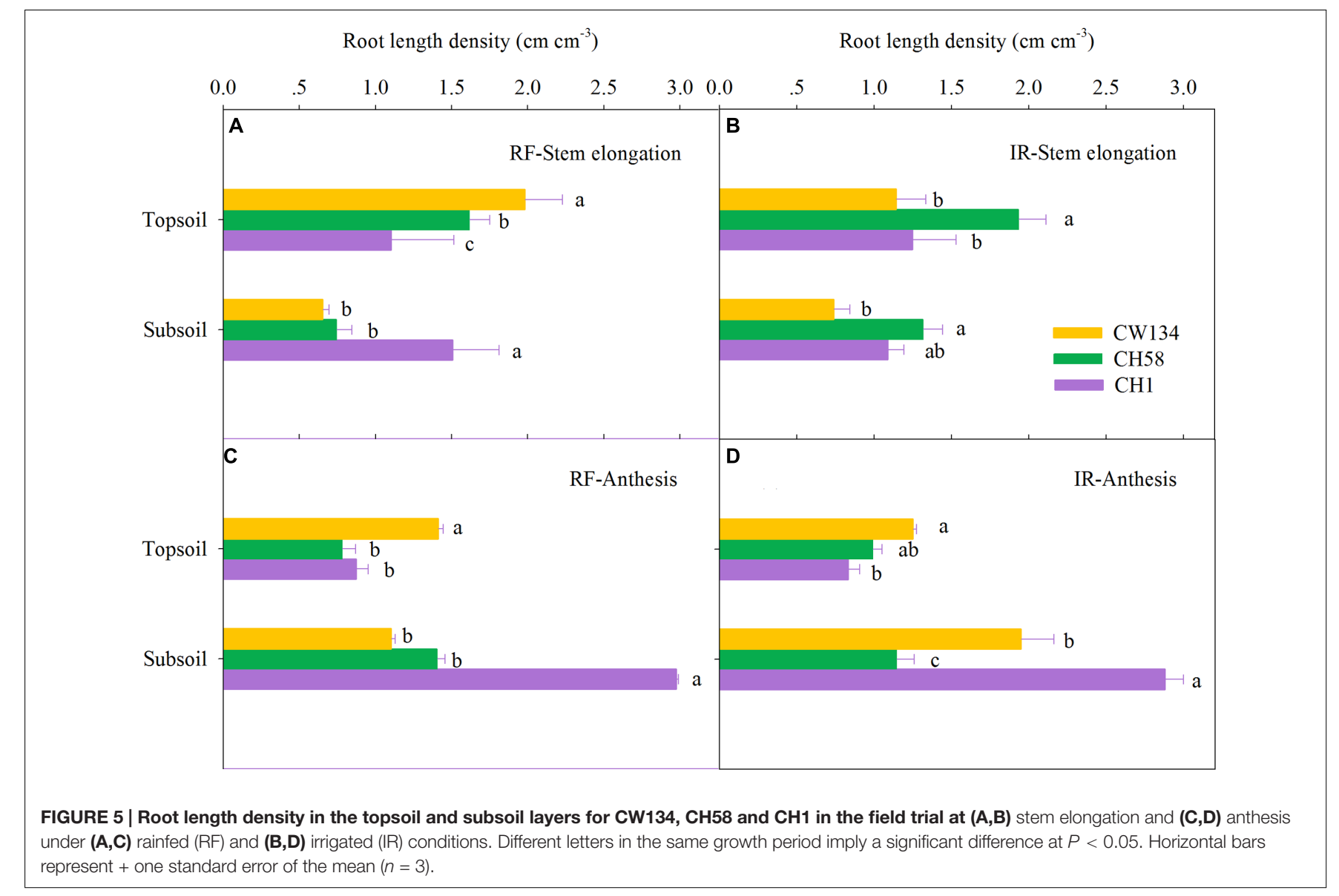

TABLE 4 | Correlation coefficients between root and yield traits in three wheat cultivars (CW134, CH58, and CH1) under moderate drought stress (MD) and well-watered conditions (WW; 2015 Rhizobox experiment), or under rainfed (RF) and irrigated (IR) conditions (2016 Field trial).

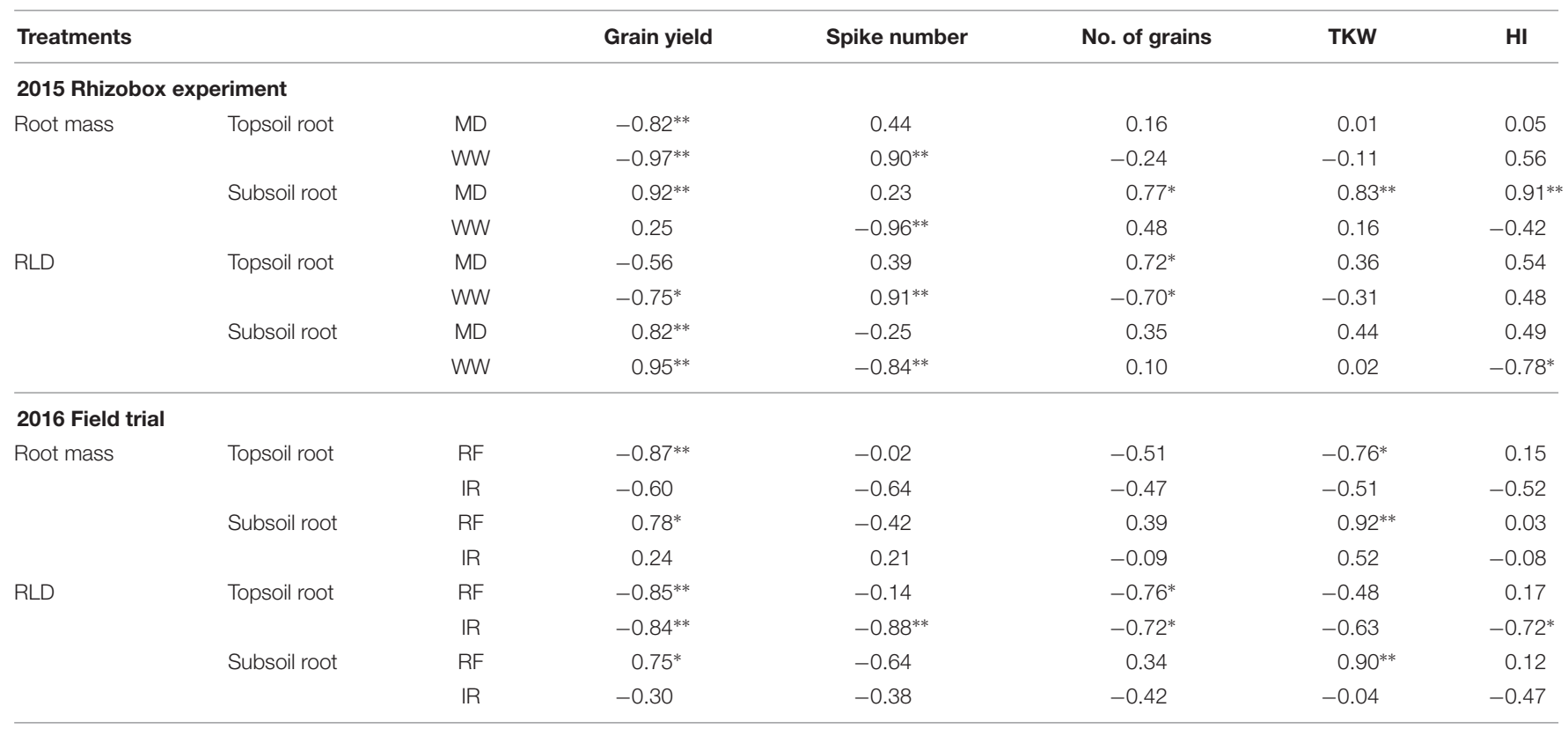

In the rhizobox experiment, root samples were collected in 2015 at maturity while in the field experiment, they were collected in 2016 at anthesis. RLD, root length density. For ANOVA results in each experiment, *, **, Significant at $P<0.05$ and 0.01 , respectively. 


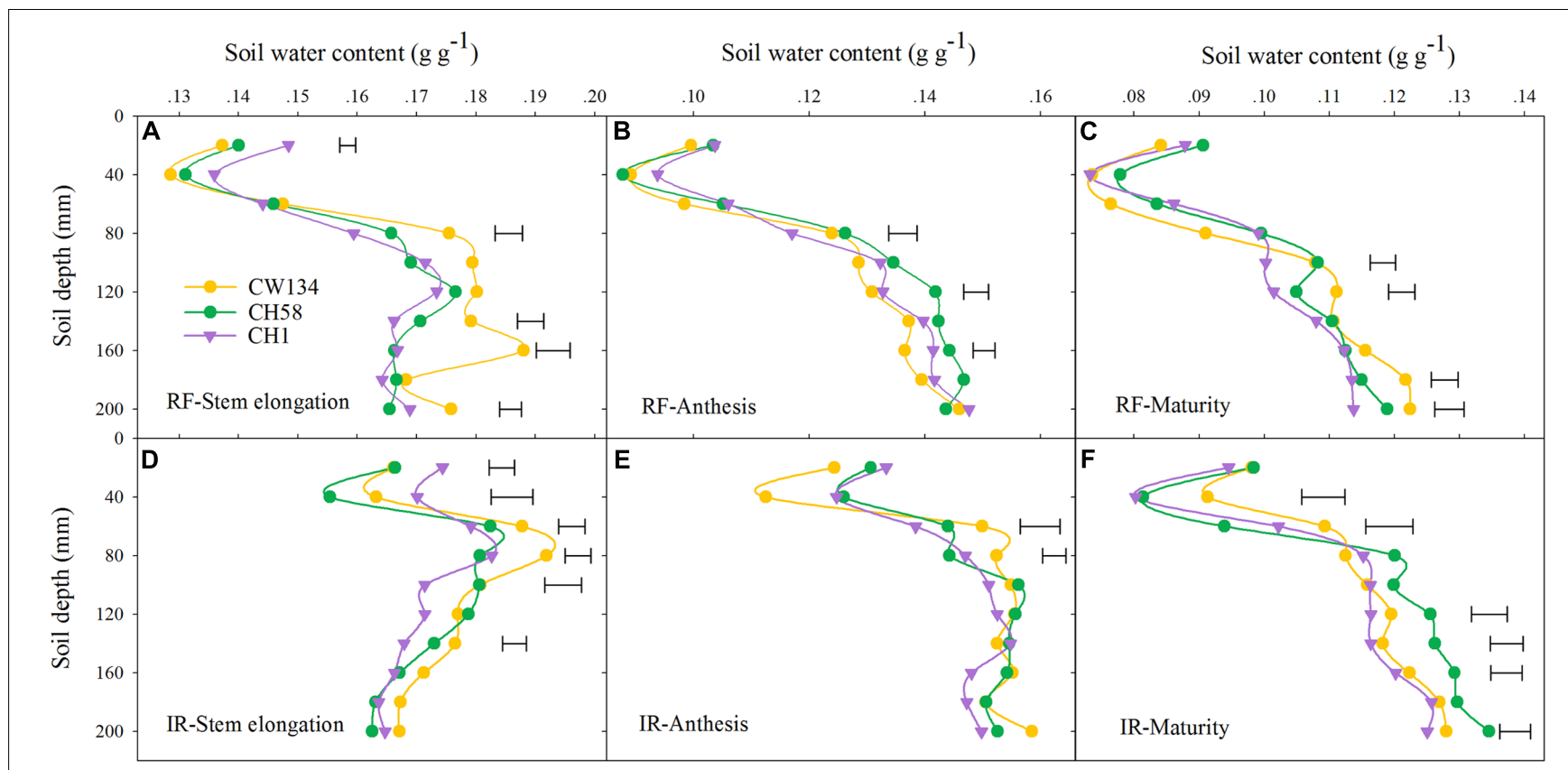

FIGURE 6 | Soil water content of CW134, CH58 and CH1 in the field trial at (A,D) stem elongation, (B,E) anthesis and (C,F) maturity under (A-C) rainfed (RF) and (D-F) irrigated (IR) conditions. Horizontal bars represent I.s.d at $P<0.05(n=3)$.

\section{DISCUSSION}

\section{Grain Yield, Yield Potential, and Yield Stability}

This study found that the newly released cultivar $\mathrm{CH} 1$ and the modern cultivar $\mathrm{CH} 58$ produced significantly higher grain yield than that of the old landrace CW134. The higher grain yield in $\mathrm{CH} 1$ was primarily attributed to a greater TKW and in CH58 to more grains per unit area, which is the yield component responsible for increases in wheat grain yield (Siddique et al., 1989a; Hall and Richards, 2013). The results presented here show that the newly released cultivar $\mathrm{CH} 1$ has a higher yield potential, and increases in yield potential may correlate with the higher $\mathrm{HI}$ (Foulkes et al., 2007; del Pozo et al., 2016). Selection for higher yields in non-stressed environments has indirectly increased grain yield in many drought stress environments (Cattivelli et al., 2008). Nevertheless, further breeding is required to improve traits for better yield potential in water-stressed conditions. Positive correlations have been found between grain yield and yield potential under drought stress and non-stressed environments (Tester and Langridge, 2010; Mohammadi et al., 2011). However, indirect selection of mean yield and yield potential genotypes under non-stressed environments may not be an appropriate choice for water-stressed environments (Abdolshahi et al., 2013). Compared with CW134 and CH1, the grain yield of the modern cultivar CH58 was more stable. Yield improvement has been associated with increased stress tolerance, which is thought to result from selection for yield stability (Tollenaar and Lee, 2002). In semi-arid area, water limitation is a crucial factor affecting crop yield. Simane et al. (1993) suggested that yield stability is a better indicator of drought resistance than yield potential. Genotypes with high yield stability should be planted in the regions with low-input systems and high yield potential in regions with high-input systems (Calderini and Slafer, 1999). The grain yield of rainfed system achieving some $5000 \mathrm{~kg} \mathrm{hm}^{-2}$ may be considered as a high input system (Song et al., 2009). In the field, winter wheat grown in the year with less rainfall than the average during the growing season could suffer drought stress causing the reduced grain yield. However, irrigation with $90 \mathrm{~mm}$ of water significantly increased the yield of three cultivars. Hence, the newly released cultivar $(\mathrm{CH} 1)$, with higher yield potential, should be more suitable for the semi-arid Loess Plateau, while the modern cultivar $(\mathrm{CH} 58)$ with higher yield stability may be planted in a dry area with lower input (no irrigation).

\section{Root and Aboveground Growth Alteration as Adaptation to Drought Stress}

A better understanding of root systems is critical to crop improvement in water-limited environments. A vigorous root system in early growth stage, with significant root mass and RLD (Palta et al., 2011), has advantages early in the growing season due to its ability to capture more water and facilitate crop establishment and growth such as faster leaf area development and shoot biomass increment (Rebetzke and Richards, 1999; Liao et al., 2006). The modern cultivar CH58, which had higher root mass and RLD during stem elongation, could be considered as an 'early vigor' genotype under well-watered condition. The lower ET of CH58 from stem elongation and anthesis may due to the 


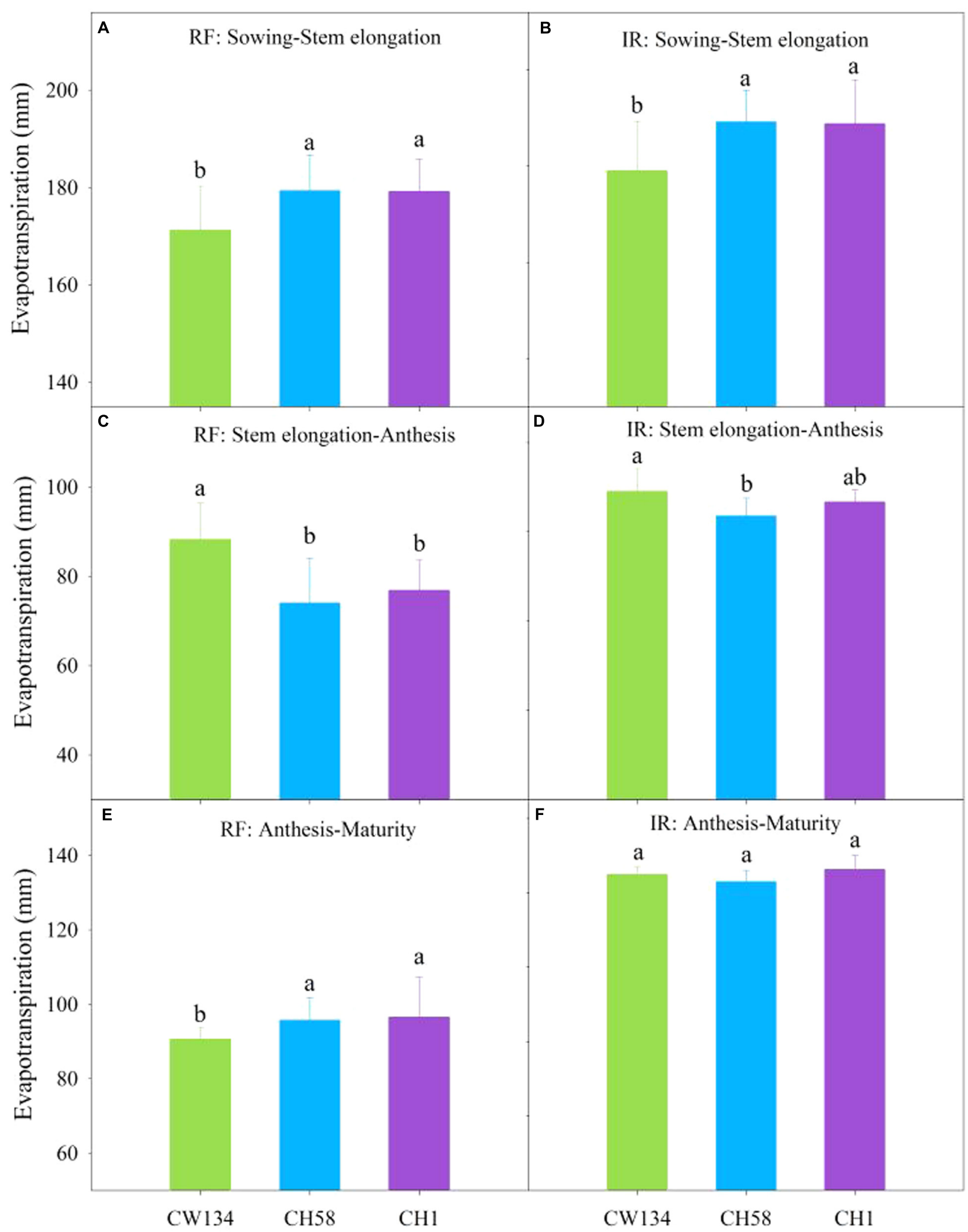

FIGURE 7 | Evapotranspiration (ET) of CW134, CH58 and CH1 in the field trial from (A,B) sowing to stem elongation, (C,D) stem elongation to anthesis and $(\mathbf{E}, \mathbf{F})$ anthesis to maturity under $(\mathbf{A}, \mathbf{C}, \mathbf{E})$ rainfed (RF) and (B,D,F) irrigated (IR) conditions. For the same growth period, bars with different letters are significantly different $(P<0.05)$. Data are means + standard error $(n=3)$. 
greater leaf area and shoot mass, which has thought to shade the soil surface and reduce water loss through soil evaporation (Botwright et al., 2002).

In the present study, root mass and RLD in the topsoil layer had a significant negative correlation with grain yield. Greater root mass, especially in topsoil layer, increases inter-root competition and delays the effectiveness of roots in capturing resources under water-stress conditions (Ma et al., 2008; Fang et al., 2011). As a consequence, an overabundance topsoil root mass may acquire more soil water for plant growth (King et al., 2003). A study in Australia found that, compared with old cultivars, modern cultivars had more grain yield and less root mass in top $40 \mathrm{~cm}$ layers (Siddique et al., 1990; Aziz et al., 2016). In our study, the old landrace cultivar CW134 had the most roots (root mass and RLD) in the topsoil layer and used more water from stem elongation to anthesis, making less soil water available to plants after anthesis, which inevitably affected grain filling. Meanwhile, the paucity of roots in the subsoil layer could not fully explore soil water in deep layer, which may explain why CW134 had the lowest grain yield. Passioura (1983) reported that less root mass in the topsoil layer would be beneficial only if more water could be utilized in deep soil layers.

The newly released cultivar $\mathrm{CH} 1$ at anthesis under drought stress had the lowest shoot mass, tiller number and leaf area per unit area. Tiller number is considered as a function of competition for light and nitrogen (Paynter and Hills, 2009). In field experiment, rainfall $(44.4 \mathrm{~mm})$ was $39 \%$ less than the long-term mean $(72.8 \mathrm{~mm})$ during vegetative growth, indicating that the plants were subjected to moderate drought conditions. $\mathrm{CH} 1$ with fewer tillers reduced soil water uptake between stem elongation and anthesis, and possibly reduced intra-plant competition simultaneously. Our results showed that $\mathrm{CH} 1$ had less root mass in the topsoil layer and less total root mass, but more root mass and higher RLD in the subsoil layers in both the nursery and field experiments. This resulted in greater extraction of water by maturity, especially at depths below $100 \mathrm{~cm}$ in the field. A higher root mass and RLD are critical for increased early vigor and pre-anthesis water use, which would improve grain yield in wheat crops which rely mainly on seasonal rainfall (Rebetzke and Richards, 1999; Liao et al., 2004). In our findings, large subsoil layer roots have positive effects on yield and yield components, especially under water stress. Higher root distribution at depth and higher RLD in the subsoil layers are considered potential traits for the adaptation of wheat to water stress, increasing the water extraction capacity in the subsoil profile for grain filling and increased grain yield (King et al., 2003; Palta et al., 2011), especially under terminal drought stress (Passioura, 1983; Gaur et al., 2008). Angus and van Herwaarden (2001) argued that, if subsoil water can be full exploitation between anthesis and grain filling, the grain yield will be increased significantly under drought stress. Lilley and Kirkegaard (2007) suggested that deep soil water is more valuable in above-average rainfall seasons because of a more efficiently conversion of deep soil water to grain. Compared with old landrace CW134, modern cultivar $\mathrm{CH} 58$ and newly released cultivar $\mathrm{CH} 1$ consumed more soil water during anthesis and maturity under drought stress condition. Each additional millimeter of water during grain filling produced $55 \mathrm{~kg} \mathrm{hm}^{-2}$ of grain at harvest (Manschadi et al., 2006). That's why higher yield were observed in both $\mathrm{CH} 58$ and $\mathrm{CH} 1$ when suffered drought stress. For CH1, more roots in subsoil and less water left in deep layer at maturity implied that the soil water could be fully exploitation, especially when soil water improved. Kirkegaard et al. (2007) found that each additional millimeter of water extracted from the subsoil (e.g., 1.35-1.85 m) after anthesis improved $62 \mathrm{~kg} \mathrm{hm}^{-2}$ yield under post-anthesis water stress This may explain that why a higher yield potential had found in the newly released cultivar $\mathrm{CH} 1$. Indeed, $\mathrm{CH} 1$ had the highest TKW which was positively correlated with subsoil root mass and RLD. $\mathrm{CH} 1$ reduced water use during vegetative growth so that more soil water was available after anthesis, particularly at depth. Our research is consistent with those of Arai-Sanoh et al. (2014), who found that cultivars with deep rooting produced more grain yield, which was mainly due to increased TKW and resulted in a higher HI. In addition, our findings indicate that $\mathrm{CH} 58$, with the lowest root mass and RLD at anthesis under irrigation, did not maximize the extraction of water in the soil profile, and more water was left unused at the end of the season. This may explain the lower yield in $\mathrm{CH} 58$ when soil moisture improved, and that grain yield was more stable under different water conditions.

\section{CONCLUSION}

The present study showed that the three wheat cultivars have different root properties under well-watered and water stressed environments. Root system adaptive to drought stress was improved along with genetic improvements. The old cultivar (CW134) produced more topsoil root mass and less subsoil root mass throughout the growing season, which restricted access to water in the subsoil and thus limited grain yield. In contrast, the newly released cultivar $(\mathrm{CH} 1)$ simulated greater amount of root growth in subsoil enabling access to water, especially when the topsoil was drying after anthesis, leading to a higher yield potential.

\section{AUTHOR CONTRIBUTIONS}

YF, YD, and YC designed the experiments and performed data analyses. YF and JW performed the nursery experiment. YF, AW, and SQ performed the field experiment. YF, YD, BX, SZ, KS, and YC contributed to the writing and revision. All authors have read and approved the final manuscript.

\section{FUNDING}

This work was supported by Chinese Academy of Sciences ("Hundred Talent" Program, A315021449), State Key Laboratory of Soil Erosion and Dryland Farming on the Loess Plateau (Special Funds A318009902-1502, A314021403-C4), and National Natural Science Foundation of China (31471946). 


\section{REFERENCES}

Abdolshahi, R., Nazari, M., Safarian, A., Sadathossini, T. S., Salarpour, M., and Amiri, H. (2015). Integrated selection criteria for drought tolerance in wheat (Triticum aestivum L.) breeding programs using discriminant analysis. Field Crops Res. 174, 20-29. doi: 10.1016/j.fcr.2015.01.009

Abdolshahi, R., Safarian, A., Nazari, M., Pourseyedi, S., and Mohamadi-Nejad, G. (2013). Screening drought-tolerant genotypes in bread wheat (Triticum aestivum L.) using different multivariate methods. Arch. Agron. Soil Sci. 59, 685-704. doi: 10.1080/03650340.2012.667080

Acreche, M. M., Briceño-Félix, G., Sánchez, J. A. M., and Slafer, G. A. (2008). Physiological bases of genetic gains in Mediterranean bread wheat yield in Spain. Eur. J. Agron. 28, 162-170. doi: 10.1016/j.eja.2007.07.001

Angus, J. F., and van Herwaarden, A. F. (2001). Increasing water use and water use efficiency in dryland wheat. Agron. J. 93, 290-298. doi: 10.2134/agronj2001. 932290x

Arai-Sanoh, Y., Takai, T., Yoshinaga, S., Nakano, H., Kojima, M., Sakakibara, H., et al. (2014). Deep rooting conferred by DEEPER ROOTING 1 enhances rice yield in paddy fields. Sci. Rep. 4:5563. doi: 10.1038/srep05563

Araus, J. L., Slafer, G. A., Reynolds, M. P., and Royo, C. (2002). Plant breeding and drought in C-3 cereals: what should we breed for? Ann. Bot. 89, 925-940. doi: 10.1093/aob/mcf049

Aziz, M. M., Palta, J. A., Siddique, K. H. M., and Sadras, V. O. (2016). Five decades of selection for yield reduced root length density and increased nitrogen uptake per unit root length in Australian wheat varieties. Plant Soil 413, 181-192. doi: 10.1007/s11104-016-3059-y

Becker, H. C., and Leon, J. (1988). Stability analysis in plant breeding. Plant Breed. 101, 1-23. doi: 10.1111/j.1439-0523.1988.tb00261.x

Botwright, T. L., Condon, A. G., Rebetzke, G. J., and Richards, R. A. (2002). Field evaluation of early vigour for genetic improvement of grain yield in wheat. Aust. J. Agric. Res. 53, 1137-1145. doi: 10.1071/AR02007

Calderini, D. F., and Slafer, G. A. (1999). Has yield stability changed with genetic improvement of wheat yield? Euphytica 107, 51-59. doi: 10.1023/A: 1003579715714

Cattivelli, L., Rizza, F., Badeck, F. W., Mazzucotelli, E., Mastrangelo, A. M., Francia, E., et al. (2008). Drought tolerance improvement in crop plants: an integrated view from breeding to genomics. Field Crops Res. 105, 1-14. doi: 10.1016/j.fcr.2007.07.004

Chen, W., Deng, X. P., Eneji, A. E., Wang, L. L., Xu, Y., and Cheng, Y. J. (2014). Dry-matter partitioning across parts of the wheat internode during the grain filling period as influenced by fertilizer and tillage treatments. Commun. Soil Sci. Plant Anal. 45, 1799-1812. doi: 10.1080/00103624.2014. 907918

Chen, X., Hao, M. D., Xu, J. J., and Zhu, Y. L. (2011). Study on the photosynthesis characteristics in the process of wheat cultivars replacement during seventy years in Loess Plateau. Acta Agric. Boreali Occidental. Sin. 20, 42-46. doi: 10.3969/j.issn.1004-1389.2011.11.009

del Moral, L. F. G., del Moral, M. B. G., Molina-Cano, J. L., and Slafer, G. A. (2003). Yield stability and development in two- and six-rowed winter barleys under Mediterranean conditions. Field Crops Res. 81, 109-119. doi: 10.1016/s03784290(02)00215-0

del Pozo, A., Yanez, A., Matus, I. A., Tapia, G., Castillo, D., Sanchez-Jardon, L., et al. (2016). Physiological traits associated with wheat yield potential and performance under water-stress in a Mediterranean environment. Front. Plant Sci. 7:987. doi: 10.3389/fpls.2016.00987

Den Herder, G., Van Isterdael, G., Beeckman, T., and De Smet, I. (2010). The roots of a new green revolution. Trends Plant Sci. 15, 600-607. doi: 10.1016/j.tplants. 2010.08.009

Du, Y. L., Wang, Z. Y., Fan, J. W., Turner, N. C., He, J., Wang, T., et al. (2013). Exogenous abscisic acid reduces water loss and improves antioxidant defence, desiccation tolerance and transpiration efficiency in two spring wheat cultivars subjected to a soil water deficit. Funct. Plant Biol. 40, 494-506. doi: 10.1071/ fp 12250

Edmeades, G. O., Bolaños, J., Chapman, S. C., Lafitte, H. R., and Bänziger, M. (1999). Selection improves drought tolerance in tropical maize populations: I. Gains in biomass, grain yield, and harvest index. Crop Sci. 39, 1306-1315. doi: $10.2135 /$ cropsci1999.3951306x
Ehdaie, B., Alloush, G. A., and Waines, J. G. (2008). Genotypic variation in linear rate of grain growth and contribution of stem reserves to grain yield in wheat. Field Crops Res. 106, 34-43. doi: 10.1016/j.fcr.2007.10.012

Ehdaie, B., Layne, A. P., and Waines, J. G. (2012). Root system plasticity to drought influences grain yield in bread wheat. Euphytica 186, 219-232. doi: 10.1007/ s10681-011-0585-9

Fang, Y., Liu, L., Xu, B. C., and Li, F. M. (2011). The relationship between competitive ability and yield stability in an old and a modern winter wheat cultivar. Plant Soil 347, 7-23. doi: 10.1007/s11104-011-0780-4

Foulkes, M. J., Reynolds, M. P., and Sylvester-Bradley, R. (2009). Genetic improvement of grain crops-chapter 15: yield potential. Crop Physiol. 68, 355-385. doi: 10.1016/B978-0-12-374431-9.00015-3

Foulkes, M. J., Snape, J. W., Shearman, V. J., Reynolds, M. P., Gaju, O., and Sylvester-Bradley, R. (2007). Genetic progress in yield potential in wheat: recent advances and future prospects. J. Agric. Sci. 145, 17-29. doi: 10.1017/ s0021859607006740

Fufa, H., Baenziger, P. S., Beecher, B. S., Graybosch, R. A., Eskridge, K. M., and Nelson, L. A. (2005). Genetic improvement trends in agronomic performances and end-use quality characteristics among hard red winter wheat cultivars in Nebraska. Euphytica 144, 187-198. doi: 10.1007/s10681-0055811-X

Gaur, P. M., Krishnamurthy, L., and Kashiwagi, J. (2008). Improving droughtavoidance root traits in chickpea (Cicer arietinum L.) - current status of research at ICRISAT. Plant Prod. Sci. 11, 3-11. doi: 10.1626/pps.11.3

Gewin, V. (2010). Food: an underground revolution. Nature 466, 552-553. doi: $10.1038 / 466552 \mathrm{a}$

Gong, Z. T., Zhang, G. L., and Chen, Z. C. (2007). Pedogenesis and Soil Taxonomy. Beijing: Science Press.

Hall, A. J., and Richards, R. A. (2013). Prognosis for genetic improvement of yield potential and water-limited yield of major grain crops. Field Crops Res. 143, 18-33. doi: 10.1016/j.fcr.2012.05.014

Himmelbauer, M. L., Loiskandl, W., and Kastanek, F. (2004). Estimating length, average diameter and surface area of roots using two different image analyses systems. Plant Soil 260, 111-120. doi: 10.1023/b:plso.0000030171.28821.55

King, J., Gay, A., Sylvester-Bradley, R., Bingham, I., Foulkes, J., Gregory, P., et al. (2003). Modelling cereal root systems for water and nitrogen capture: towards an economic optimum. Ann. Bot. 91, 383-390. doi: 10.1093/aob/mcg033

Kirkegaard, J. A., Lilley, J. M., Howe, G. N., and Graham, J. M. (2007). Impact of subsoil water use on wheat yield. Aust. J. Agric. Res. 58, 303-315. doi: 10.1071/ AR06285

Liao, M. T., Fillery, I. R. P., and Palta, J. A. (2004). Early vigorous growth is a major factor influencing nitrogen uptake in wheat. Funct. Plant Biol. 31, 121-129. doi: 10.1071/FP03060

Liao, M. T., Palta, J. A., and Fillery, I. R. P. (2006). Root characteristics of vigorous wheat improve early nitrogen uptake. Aust. J. Agric. Res. 57, 1097-1107. doi: 10.1071/ar05439

Lilley, J. M., and Kirkegaard, J. A. (2007). Seasonal variation in the value of subsoil water to wheat: simulation studies in southern New South Wales. Aust. J. Agric. Res. 58, 1115-1128. doi: 10.1071/AR07046

Loss, S. P., and Siddique, K. H. M. (1994). Morphological and physiological traits associated with wheat yield increases in mediterranean environments. $A d v$. Agron. 52, 229-276. doi: 10.1016/s0065-2113(08)60625-2

Ma, S. C., Xu, B. C., Li, F. M., Liu, W. Z., and Huang, Z. B. (2008). Effects of root pruning on competitive ability and water use efficiency in winter wheat. Field Crops Res. 105, 56-63. doi: 10.1016/j.fcr.2007.07.005

Manschadi, A. M., Christopher, J., Devoil, P., and Hammer, G. L. (2006). The role of root architectural traits in adaptation of wheat to water-limited environments. Funct. Plant Biol. 33, 823-837. doi: 10.1071/FP06055

Manske, G. G. B., and Vlek, P. L. G. (2002). "Root architecture-wheat as a model plant," in Plant Roots: The Hidden Half, ed. Y. Waisel (New York, NY: Marcel Dekker), 249-259. doi: 10.1201/9780203909423.ch15

Mohammadi, M., Karimizadeh, R., and Abdipour, M. (2011). Evaluation of drought tolerance in bread wheat genotypes under dryland and supplemental irrigation conditions. Aust. J. Crop Sci. 5, 487-493.

Palta, J. A., Chen, X., Milroy, S. P., Rebetzke, G. J., Dreccer, M. F., and Watt, M. (2011). Large root systems: are they useful in adapting wheat to dry environments? Funct. Plant Biol. 38, 347-354. doi: 10.1071/fp11031 
Palta, J. A., and Yang, J. C. (2014). Crop root system behaviour and yield preface. Field Crops Res. 165, 1-4. doi: 10.1016/j.fcr.2014.06.024

Passioura, J. B. (1983). "Roots and drought resistance," in Developments in Agricultural and Managed Forest Ecology, eds S. F. John and O. W. Wayne (Amsterdam: Elsevier), 265-280.

Paynter, B. H., and Hills, A. L. (2009). Barley and rigid ryegrass (Lolium rigidum) competition is influenced by crop cultivar and density. Weed Technol. 23, 40-48. doi: 10.1614/wt-08-093.1

Ramachandra Reddy, A., Chaitanya, K. V., and Vivekanandan, M. (2004). Drought-induced responses of photosynthesis and antioxidant metabolism in higher plants. J. Plant Physiol. 161, 1189-1202. doi: 10.1016/j.jplph.2004. 01.013

Raza, A., Imtiaz, M., and Mohammad, W. (2015). "Wheat root selections for sustainable production," in Sustainable Agriculture Reviews, Vol. 18, ed. E. Lichtfouse (Switzerland: Springer), 295-315. doi: 10.1007/978-3-31921629-4_10

Rebetzke, G. J., and Richards, R. A. (1999). Genetic improvement of early vigour in wheat. Aust. J. Agric. Res. 50, 291-301. doi: 10.1071/A98125

Reynolds, M., Dreccer, F., and Trethowan, R. (2007). Drought-adaptive traits derived from wheat wild relatives and landraces. J. Exp. Bot. 58, 177-186. doi: $10.1093 / j x b / e r 1250$

Reynolds, M. P., Delgado, B. M. I., Gutiérrez-Rodrìguez, M., and LarquéSaavedra, A. (2000). Photosynthesis of wheat in a warm, irrigated environment: I: genetic diversity and crop productivity. Field Crops Res. 66, 37-50. doi: 10.1016/S0378-4290(99)00077-5

Richards, R. A., Rebetzke, G. J., Condon, A. G., and van Herwaarden, A. F. (2002). Breeding opportunities for increasing the efficiency of water use and crop yield in temperate cereals. Crop Sci. 42, 111-121. doi: 10.2135/cropsci20 02.1110

Siddique, K. H. M., Belford, R. K., Perry, M. W., and Tennant, D. (1989a). Growth, development and light interception of old and modern wheat cultivars in a Mediterranean-type environment. Aust. J. Agric. Res. 40, 473-487. doi: 10.1071/ AR9890473

Siddique, K. H. M., Belford, R. K., and Tennant, D. (1990). Root: shoot ratios of old and modern, tall and semi-dwarf wheats in a Mediterranean environment. Plant Soil 121, 89-98. doi: 10.1007/bf00013101

Siddique, K. H. M., Kirby, E. J. M., and Perry, M. W. (1989b). Ear:stem ratio in old and modern wheat varieties; relationship with improvement in number of grains per ear and yield. Field Crops Res. 21, 59-78. doi: 10.1016/0378-4290(89) 90041-5

Simane, B., Struik, P. C., Nachit, M. M., and Peacock, J. M. (1993). Ontogenetic analysis of yield components and yield stability of durum wheat in water-limited environments. Euphytica 71, 211-219. doi: 10.1007/bf00040410

Slafer, G. A., and Kernich, G. C. (1996). Have changes in yield (1900-1992) been accompanied by a decreased yield stability in Australian cereal production? Aust. J. Agric. Res. 47, 323-334. doi: 10.1071/ar9960323
Song, L., Li, F. M., Fan, X. W., Xiong, Y. C., Wang, W. Q., Wu, X. B., et al. (2009). Soil water availability and plant competition affect the yield of spring wheat. Eur. J. Agron. 31, 51-60. doi: 10.1016/j.eja.2009.03.003

Sun, Y. Y., Wang, X. L., Wang, N., Chen, Y. L., and Zhang, S. Q. (2014). Changes in the yield and associated photosynthetic traits of dry-land winter wheat (Triticum aestivum L.) from the 1940s to the 2010s in Shaanxi Province of China. Field Crops Res. 167, 1-10. doi: 10.1016/j.fcr.2014.07.002

Tester, M., and Langridge, P. (2010). Breeding technologies to increase crop production in a changing world. Science 327, 818-822. doi: 10.1126/science. 1183700

Tollenaar, M., and Lee, E. A. (2002). Yield potential, yield stability and stress tolerance in maize. Field Crops Res. 75, 161-169. doi: 10.1016/S0378-4290(02) 00024-2

Wang, J., Liu, W. Z., Mu, H. F., and Dang, T. H. (2010). Inorganic phosphorus fractions and phosphorus availability in a calcareous soil receiving 21-year superphosphate application. Pedosphere 20, 304-310. doi: 10.1016/S10020160(10)60018-5

Zhang, D. Y., Sun, G. J., and Jiang, X. H. (1999). Donald's ideotype and growth redundancy: a game theoretical analysis. Field Crops Res. 61, 179-187. doi: 10.1016/s0378-4290(98)00156-7

Zhang, X. Y., Chen, S. Y., Sun, H. Y., Wang, Y. M., and Shao, L. W. (2010). Water use efficiency and associated traits in winter wheat cultivars in the North China Plain. Agric. Water Manage. 97, 1117-1125. doi: 10.1016/j.agwat.2009.06.003

Zhang, Y., Hao, M. D., Pang, Y. H., and Fan, H. L. (2009). Study on evolution of species traits and quality characters of Changwu brand in dryland of the Loess Plateau. Acta Agric. Boreali Occidental. Sin. 18, 65-70. doi: 10.3969/j.issn.10041389.2009.01.015

Zheng, T. C., Zhang, X. K., Yin, G. H., Wang, L. N., Han, Y. L., Chen, L., et al. (2011). Genetic gains in grain yield, net photosynthesis and stomatal conductance achieved in Henan Province of China between 1981 and 2008. Field Crops Res. 122, 225-233. doi: 10.1016/j.fcr.2011.03.015

Zhu, L., and Zhang, D. Y. (2013). Donald's Ideotype and growth redundancy: a pot experimental test using an old and a modern spring wheat cultivar. PLoS ONE 8:e70006. doi: 10.1371/journal.pone.0070006

Conflict of Interest Statement: The authors declare that the research was conducted in the absence of any commercial or financial relationships that could be construed as a potential conflict of interest.

Copyright (c) 2017 Fang, Du, Wang, Wu, Qiao, Xu, Zhang, Siddique and Chen. This is an open-access article distributed under the terms of the Creative Commons Attribution License (CC BY). The use, distribution or reproduction in other forums is permitted, provided the original author(s) or licensor are credited and that the original publication in this journal is cited, in accordance with accepted academic practice. No use, distribution or reproduction is permitted which does not comply with these terms. 